\title{
MULTISENSOR DATA FUSION FOR CULTURE HERITAGE ASSETS MONITORING AND PREVENTIVE CONSERVATION
}

\author{
V. Cera ${ }^{1}$ \\ ${ }^{1}$ Department of Architecture, Federico II University of Naples, Italy, valeria.cera@unina.it
}

Commission II

KEY WORDS: data fusion, monitoring, preventive conservation, close-range sensing

\begin{abstract}
:
This paper shows the first phase of an ongoing interdisciplinary research project aimed at codifying procedures for the control and non-destructive analysis of the conservation status of $\mathrm{CH}$ artefacts to guide preventive preservation actions. It specifically explains the results of an experiment aimed at defining the procedural phases of semantic-informative enrichment of a digital architectural model where the morpho-metric components acquired with instrumental survey techniques are linked with cognitive and technical aspects (microclimatic, material, and geometric deviation data), with the aim of making this model a support for the simulation of scenarios connected to preventive preservation programmes.

The research was carried out on the church of San Michele Arcangelo in Padula, affected by plaster detachment from the frescoes on the intrados of the vaulted systems. The work was conceived to support a mainly qualitative assessment regarding a possible relationship between micro-environmental variations and visually perceived degradation phenomena to provide a first indication of the conservation status of the investigated surfaces. The analyses were conducted through algorithms that, as such, are repeatable and objective. In addition, these processes, as they were applied to the models derived from the architectural survey, made it possible to make the most of these outputs. Therefore, by combining the algorithmic manipulation of the digital representations with the necessary critical interpretation of the data by the specialist, it was possible to address some actions of direct intervention and guide the most appropriate choices for subsequent in-depth diagnostics, more targeted, reducing the damage to the historical heritage.
\end{abstract}

\section{INTRODUCTION}

Preventive conservation is today an open research topic: the multiple risk factors to which built cultural heritage assets are subjected make it increasingly urgent to find tools and methods through which to safeguard the various assets from ruin. The contemporary approach is not limited, however, to the formulation of operational intervention methodologies, as represented by the restoration project. It tends towards the study of processes that can inform on the state of health of the heritage and to monitor it over time, acquiring useful data to direct the diagnostic investigation in a completely non-invasive way.

An adequate intervention programme requires a collection of heterogeneous data: information on the spatial distribution of the architecture, metric quantities, formal matrices, semantic and topological relational data. In addition, there are also documents that refer to different disciplines and that are related to the materials, the colours, the degenerative state of the surfaces, the static nature of the structures, and the environmental conditions. Collecting this corpus of knowledge, however, often requires investigations that are invasive to historic architecture. For this reason, 3D models obtained through architectural survey processes have begun to be used as a source of diverse data. The point cloud is a set of entities from which knowledge can be extracted through mathematical algorithms. This information can inform about the nature and behaviour of surface materials, the evolution of pathologies, alterations, and surface degradations. Furthermore, it is possible to associate the same points with further information, fundamental for restoration diagnostics, such as environmental data of temperature and humidity. The proposed research is part of this context.

This paper shows the first phase of an ongoing interdisciplinary research project aimed at codifying procedures for the control and non-destructive analysis of the conservation status of cultural heritage artefacts to guide preventive preservation actions.
The research is organised in 3 macro-actions: (i) Multi-scalar digitisation and hetero-informative characterisation of the semantically decomposed cultural heritage artefact; (ii) Design and simulation of the remote system for continuous monitoring of the real artefact for updating the digital information twin; (iii) Scenario simulations to orient preventive conservation actions and support decision-making processes.

This essay specifically concerns the first action of the project and explains the results of an experiment aimed at defining the procedural phases of semantic-informative enrichment of a digital architectural model where the morpho-metric components acquired with instrumental survey techniques are linked with cognitive and technical aspects (microclimatic, material and geometric deviation data), with the aim of making this model a support for the simulation of scenarios connected to preventive preservation programmes.

The research was carried out on the church of San Michele Arcangelo in Padula, affected by plaster detachment from the frescoes on the intrados of the vaulted systems.

\section{RELATED WORKS}

More and more widespread are those tools and techniques capable of acquiring, in a non-invasive and non-destructive (NDT) manner for the structures concerned, a series of data useful for Preventive Conservation actions (PC).

In this framework, there are some researches aimed at testing processes able on the one hand to integrate with other cognitive data, and on the other hand to widen, from an informative point of view, the database underlying the 3D models achievable with the architectural survey techniques, which are already valuable cognitive systems in themselves.

The first group involves several studies (Bakalos et al. 2020; Dong et al. 2019) in which the profitable use of thermographic, hyper-spectral and radar images in the diagnostics and 
monitoring of the cultural heritage has been widely demonstrated.

Similarly, there are several projects (Lee and Lee, 2020; Cera and Garcia, 2018) that have been interested in experimenting with discrete point cloud model direct manipulation methods in order to extrapolate informative descriptors from the model itself (e.g., taken from reflectance maps, geometric deviation maps) that are useful for providing information about the degenerative state of surfaces. The only major limitation that was evident until a few years ago was the high cost of the tools and the cumbersome nature of the operations required to link the data, which has now been largely overcome thanks to the commercialisation of sensors and computer processors capable of supporting and achieving true integration of heterogeneous data (Adamopoulos and Rinaudo, 2021; Dahaghin et al., 2021).

Hence the research presented in this essay, which is part of a scientific collaboration agreement between the Interdepartmental Research Centre Urban|Eco of the University of Naples Federico II and Diocese of Teggiano-Policastro.

\section{CASE STUDY}

The investigation has been conducted about the church of San Michele Arcangelo, Cathedral of Padula town, with a remarkable historical and artistic value. Dating back to the 9th-10th century, the church has been an iconic feature of Padula town since its own foundation, being located on top of the historical center, in contrast to the position of the Charterhouse of San Lorenzo, located at its bottom. Over the centuries, from the Norman era to the post-war period, the cathedral has undergone several reconstructions, consolidation and restoration works. Today, the cathedral is almost baroque in style, with a double order façade, marked by double pilasters, three entrances and a tympanum. The hall is divided into three naves adorned with minor side altars, the presbytery and polygonal apse are pronounced in comparison to the size of the transept, which is constrained by the width of the hall. The sacristy, the baptismal font and two other service rooms are located along the right side of the nave, while on the left is the three-storey square bell tower. The decorative style of the interior tends towards Baroque and largely uses stucco ornament. Precious marble and Padula stone work characterizes the cathedral's artistic collection, which also includes admirable wooden sculptures by the famous Cariello family of artists and engravers.

Several fresco cycles adorn the vaulted roof systems, mainly by the artist Rocco Pennino and dating from 1954. Among these, the figures on the dome covering the transept today show the signs of the most serious deterioration, with phenomena that can be attributable to the detachment of the surface plaster (Fig. 1).

\section{DEVELOPED METHODOLOGY}

The research activities were organised in several phases, which in turn were divided into sub-phases:

1) creation of a multiscalar 3D model:

i) TLS survey to acquire a general point cloud.

ii) optical triangulation scanner survey to refine the geometric data for specific portions.

iii) detailed terrestrial photogrammetric survey to refine the colorimetric data.

2) extension of the information base:

i) semantic segmentation of the model.

ii) cataloguing and mapping of materials.

iii) acquisition of thermographic images.

3) integration and critical analysis of the data recorded for the damaged parts:

i) analysis of reflectance maps. ii) analysis of thermal images.

iii) study of geometric deviation.
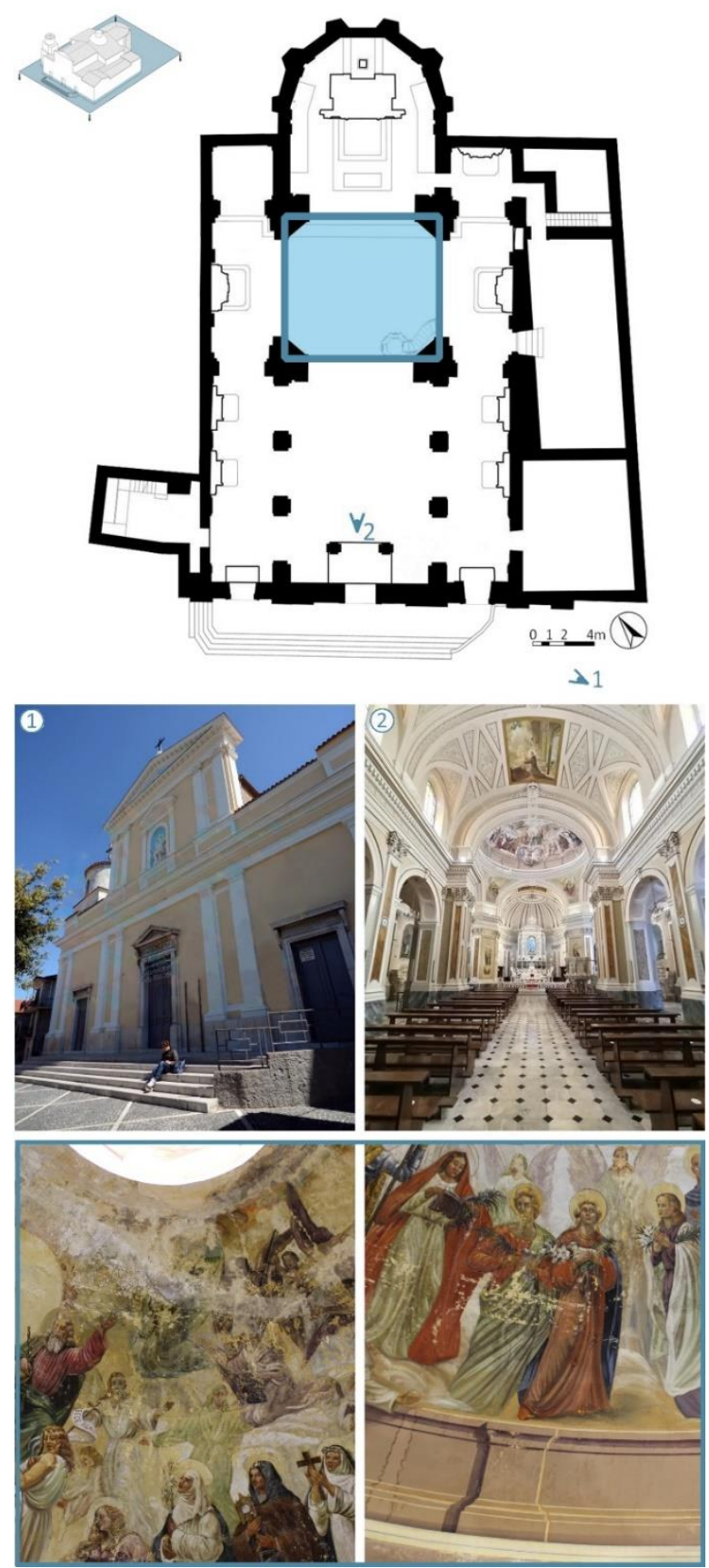

Figure 1. Church of San Michele Arcangelo in Padula. Plan and photographs of the façade and interior. Detailed images of the damaged frescoes of the dome.

\subsection{Definition and semantic characterisation of the geometrical-informative model}

The entire church was surveyed with a TLS Faro Focus3D X330, set to an average resolution of $6 \mathrm{~mm}$ at a distance of 10 metres and an accuracy of $4 x$. The pitch of the range maps of approximately $3 \mathrm{~mm}$ at 5 metres was suitable for surveying an interior rich in carved decorations and ornaments.

In order to have an orderly and uniform acquisition network, regularly distributed in the space of the cathedral, the acquisition 
of 37 scans was defined with a maximum controlled distance between range maps of approximately 10 metres.

The stationing of the scans was also planned taking into account the variables that have the greatest influence on the reflectance data: reduction of the shadow zones, evaluation of the pick-up angle, analysis of the angle of incidence of the structured light on the materials, distance from the object. Through best-fitting procedures of geometric primitives, the single point clouds were rotated and translated by the origin of the local reference system - coincident with station no. 1 - aligned and recorded. The tension recorded between the different targets at the end of the procedure is in the order of a millimeter. The automatic process did not return any alignment errors.

The resulting cloud was used as a starting point for the subsequent steps of informative expansion and deepening of the details. First of all, traditional 2D graphics were prepared, obtained by manipulation and integration of the lines automatically extracted from orthophotos, obtained by setting cutting planes of the points cloud, with both horizontal and vertical orientation (Fig. 2).
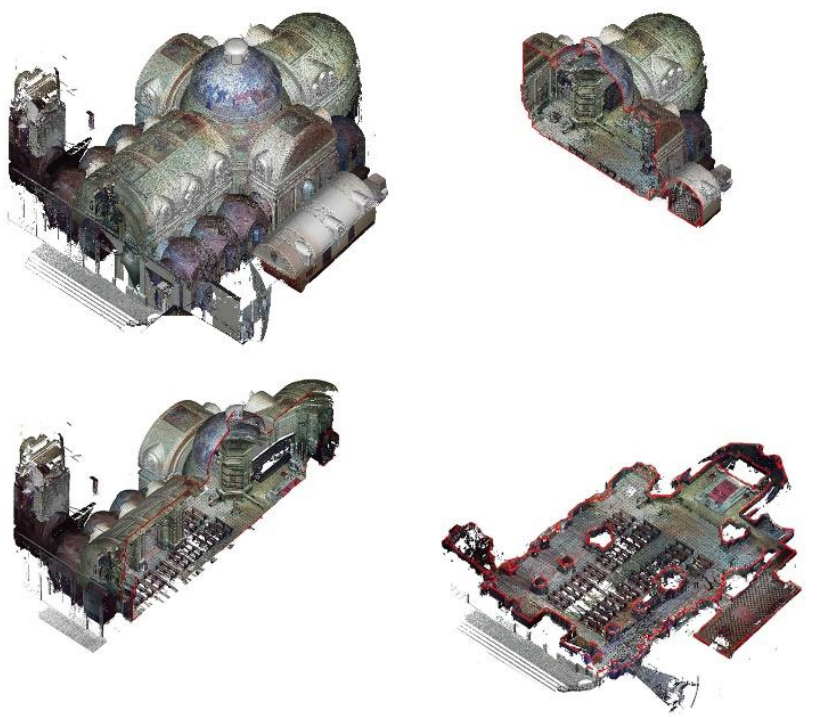

Figure 2. TLS point cloud. Section operations with horizontal and vertical planes for the extraction of orthophotos.

These drawings - plans, sections and hypography - were necessary in order to satisfy to the request of updated documentation from the authorities involved in the restoration, rehabilitation and protection, with a view to long-term preventive conservation. For this reason, the drawings were enriched with the cataloguing and mapping of the existing materials; the last operation was also related to the conceptual semantic segmentation of the model in order to orientate the subsequent critical analyses.

The identification of distinctive elements from a semantic point of view in historical buildings is a complex operation, even more if it is sacral architecture. It implies ambiguity and uncertainty (Cera and Campi, 2021) for which some annotation methods have been formulated (Cera, 2020) in conjunction with studies on the application of machine learning and deep learning algorithms to optimize the analysis time and decomposition of models (Croce et al., 2021; Matrone et al., 2020).

In this paper, benefiting from some theoretical approaches (Colucci et al., 2021; Brumana et al., 2019; Capone et al., 2019), we referred on the one hand to the Art and Architecture Tesaurus - AAT- of the Getty Institute for the identification of concepts in the domain of interest; on the other hand, to historical treatises and specific manuals on sacral architecture for the geometric perimeter of the macro and micro semantic components (Fig. 3).
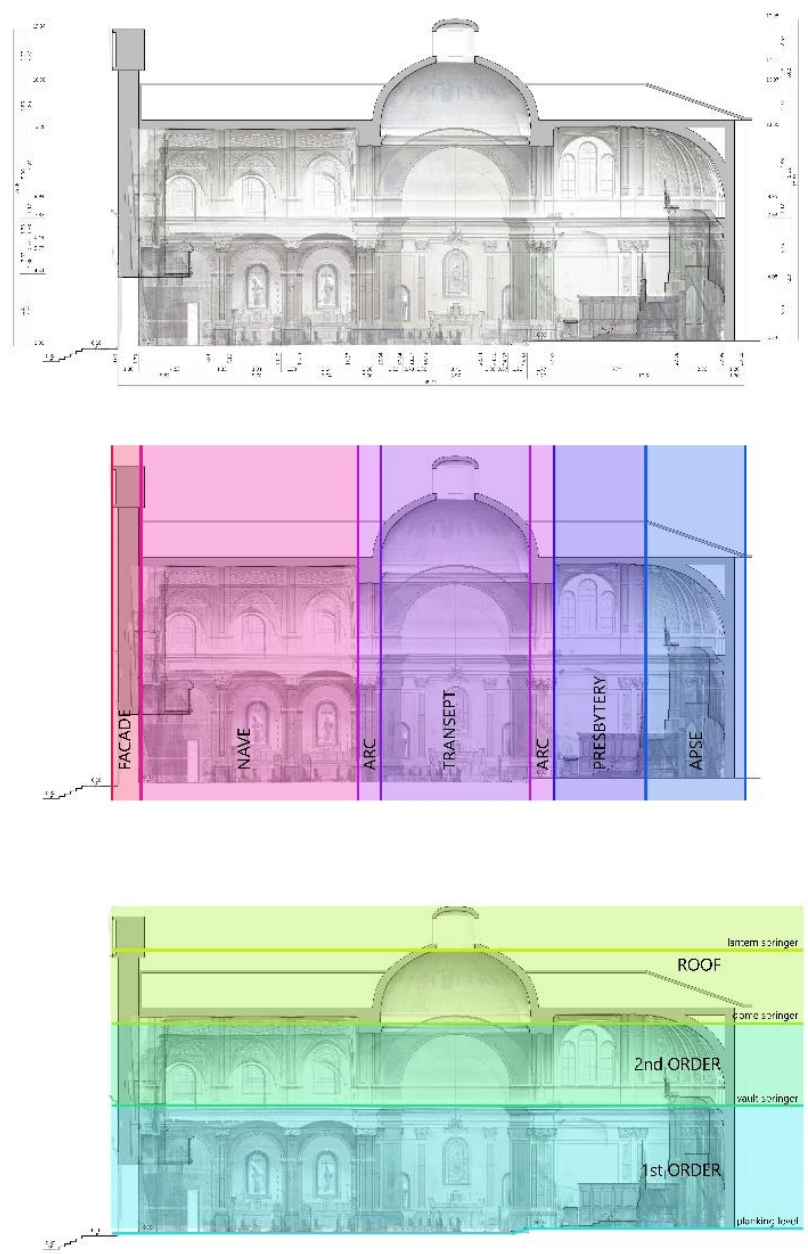

Figure 3. Traditional technical drawings related to the semantic conceptual segmentation of the model according to the AAT thesaurus and historical treatises.

Once the model of the church had been semantically broken down into conceptual form, analysis and mapping sheets were produced for the main materials present, organized in a critical manner and related to the semantic elements, which the cathedral was divided. The graphic representation of the catalogued materials follows the indications of the Italian standard UNI 3972:1981 for the graphic representation of architectural materials.

The catalogued materials have also been associated with a sampling of their respective colors; this result has been obtained, in this first cognitive phase, with a computerized recognition system, based on the comparison with a computerized color catalogue. Each color is expressed both in the additive RGB color model and in the subtractive CMYK model, in order to take into account both the digital/informative aspect of color-sampling and the printing of the schedules produced (Fig. 4).

\subsection{Information enrichment and processing of the multiscale model}

The analysis of the drawings revealed the presence of degradation and alteration phenomena mainly located on the intrados of the dome covering the transept of the hall. On these elements, the information database has deepened: (i) in terms of 
accuracy and metric-formal precision through the integration of acquisitions with a FARO Freestyle3D triangulation scanner; (ii) with reference to the quality of the colorimetric data of the surface texture with an image-based survey with a CanonEos1300D reflex camera and (iii) in terms of thematic expansion of the information collection with the contextual recording of thermal images and humidity values.
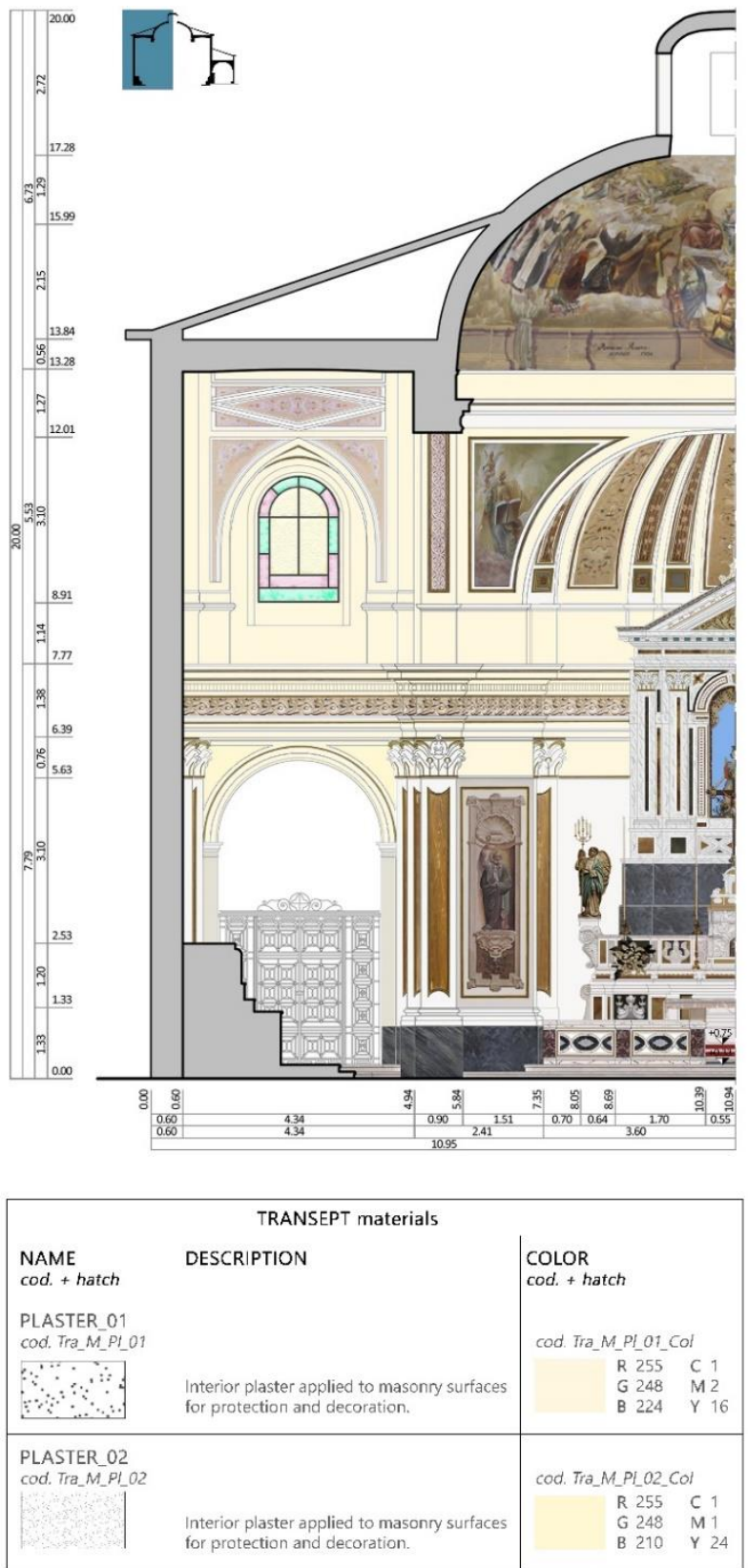

Figure 4. Example of filing and mapping of materials and their colours in relation to the architectural space, segmented and annotated with the semantic concept of "transept".

The thermographic collection was carried out at two different times, corresponding to two different seasons. The first took place on 4 August 2020 with the use of a FLIR E40bx thermal camera (resolution of IR images 320x240 pixels), used at two different distances from the surfaces: 1.70 metres above ground level, with a distance of about 15.50 metres from the dome, and
10.30 metres from the ground (with the aid of a scaffold), with a distance of about 2.80 metres from the intrados of the dome

The surface thermal data were recorded taking into account the tabular value of the emissivity of the material of the dome frescoes, i.e., ochre lime plaster, average between dark and light colours, $\mathrm{e}=0.97$. During the acquisition, the ambient temperature and relative humidity values were also recorded, respectively 24.3 degrees Celsius and 66\%, with the use of a FLIR MR77 hygrometer.

The second collection of thermal data was carried out on 8 February 2021, using a TESTO890 camera, characterised with a better resolution than the previous one (basic resolution of $640 \mathrm{x}$ 480 pixels expandable to $1280 \times 960$ pixels) and greater processability in the SfM software, placed on a tripod at approximately 1.70 metres from the floor. The choice of the stationary height was dictated by the results of an initial analysis of the previously acquired thermograms (Cera, 2021). Although the thermograms were acquired at different distances from the object, the images show the same data quality and the same quantitative variation of the temperature value, making it evident that the distance from the object did not influence the recorded values.

For each thermal shot, a photograph was also recorded in the visible range with the reflex camera placed on the same tripod so that the optical centres of the two sensors coincided during the processing phase. Within the 3DF Zephyr software, the SLR frames were first oriented and processed. Taking advantage of the coincidence of the optical centres, the thermal images were then selected as the origin of the data. From the previously reconstructed dense cloud, information on the thermal behaviour of the surfaces was projected onto the individual points of the cloud. In order to refine the data in terms of metric accuracy and to enrich it with the reflectance information recorded by the laser scanner, the two clouds were integrated by means of Control Points, assuming the TLS data as the reference system. The result of the entire data integration process is a discrete 3D model in which for each point the temperature, reflectance and colour data are now provided with the position in space.

\section{DATA ANALYSIS AND RESULTS}

In order to create a multilevel information archive, the next step was to extract additional descriptors from the collected data. First of all, the hue intensity images from TLS were manipulated, considering only those scans having as focus the intrados frescoes and examining them individually in order to avoid doubts on the reliability of the data obtainable from the "united" cloud, subject to the variability of the inclination angle and the distance of the laser pulse from the surface of interest

The reflectance variation detected, considering the type of the impulse emitted, is consistent with the laboratory spectra in the literature and closely correlated to the colorimetric variation of the pictorial finishing layer. The hue intensity image, in fact, shows, in a complete percentage range, less reflective areas, close to the dome's springer, with a range of variability equal to 30$35 \%$, and specific parts with higher reflectance, from $62 \%$ to $75 \%$, with a low absorption of the laser beam. Given the wavelength of the pulse emitted in the infrared spectrum of $1550 \mathrm{~nm}$, the data is entirely consistent with the behaviour of the plaster. In particular, blue lime plaster, $30 \%$; natural lime plaster, $60 \%$; yellow ochre lime plaster, $70 \%$; red ochre lime plaster, $65 \%$.

At a first impression, shown in (Cera, 2021), the reflectance map with these intervals seems not to reveal significant data for the areas affected by the plaster detachment. In fact, these areas are not distinguishable by shape in the colour palette, showing, on 
the contrary, part of areas with homogeneous macroscopic behaviour (Fig. 5a, 5b).
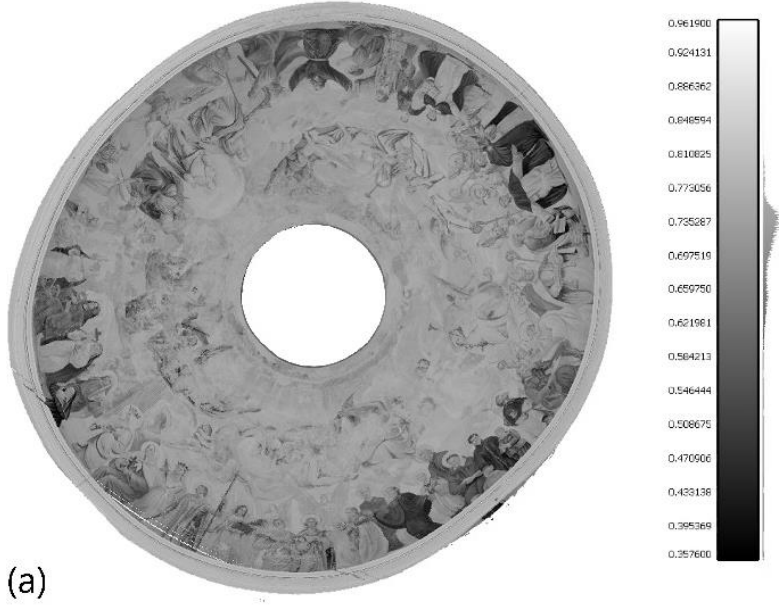

(b)
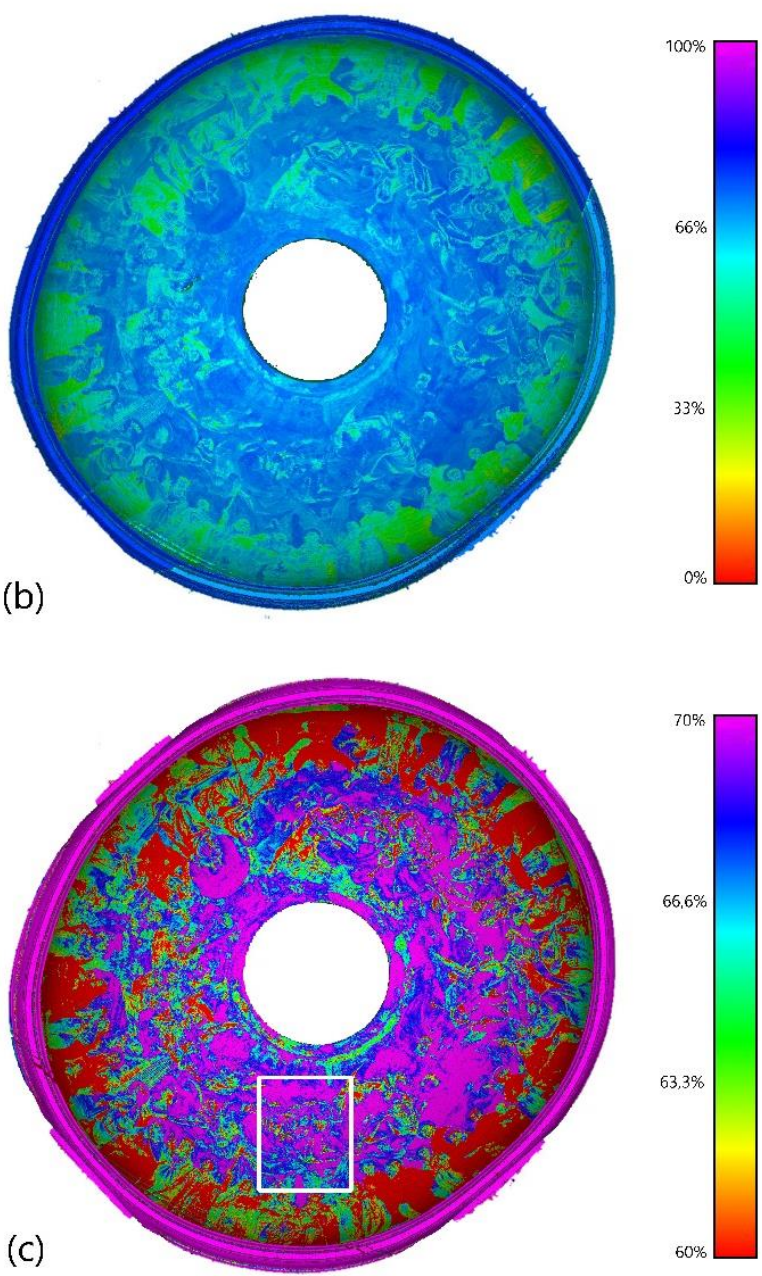

Figure 5. Manipulation of the reflectance maps obtained with the TLS survey $(a, b)$. By varying the range of the percentage value (c) it is possible to extract progressively more significant information for the damaged portions of the fresco.

Supported by visual and photographic investigation of the surfaces, the study was detailed for those parts of the frescoes that appear visually affected. Considering, therefore, only the portions of the map comprising the damaged sections, the ranges of values were manipulated, working in steps of 5 and 10 percentage points. The resulting new map now shows more clearly small, isolated areas, with reflection values around $60 \%$, in contrast to the macroscopic behaviour of the surrounding region (Fig. 5c). The geometry of these small areas can be traced back to those areas affected by the plaster detachment. These can now be easily traced back to the pathological phenomenon and not to a chromatic variation of the finishing layer since they are located in areas where the figurative continuity of the representation is clearly interrupted (Fig. 6).

To support this new consideration, the investigation was deepened by cross-referencing the variations in reflectance with the thermal states. Both in summer and winter, the thermographic reading reveals the presence of 4 cold areas descending from the lantern towards the springer, with a lower temperature ( 0.8 or 1.9 degrees depending on the season) than the surrounding areas and much more extensive than the visually affected parts (Fig. 7).
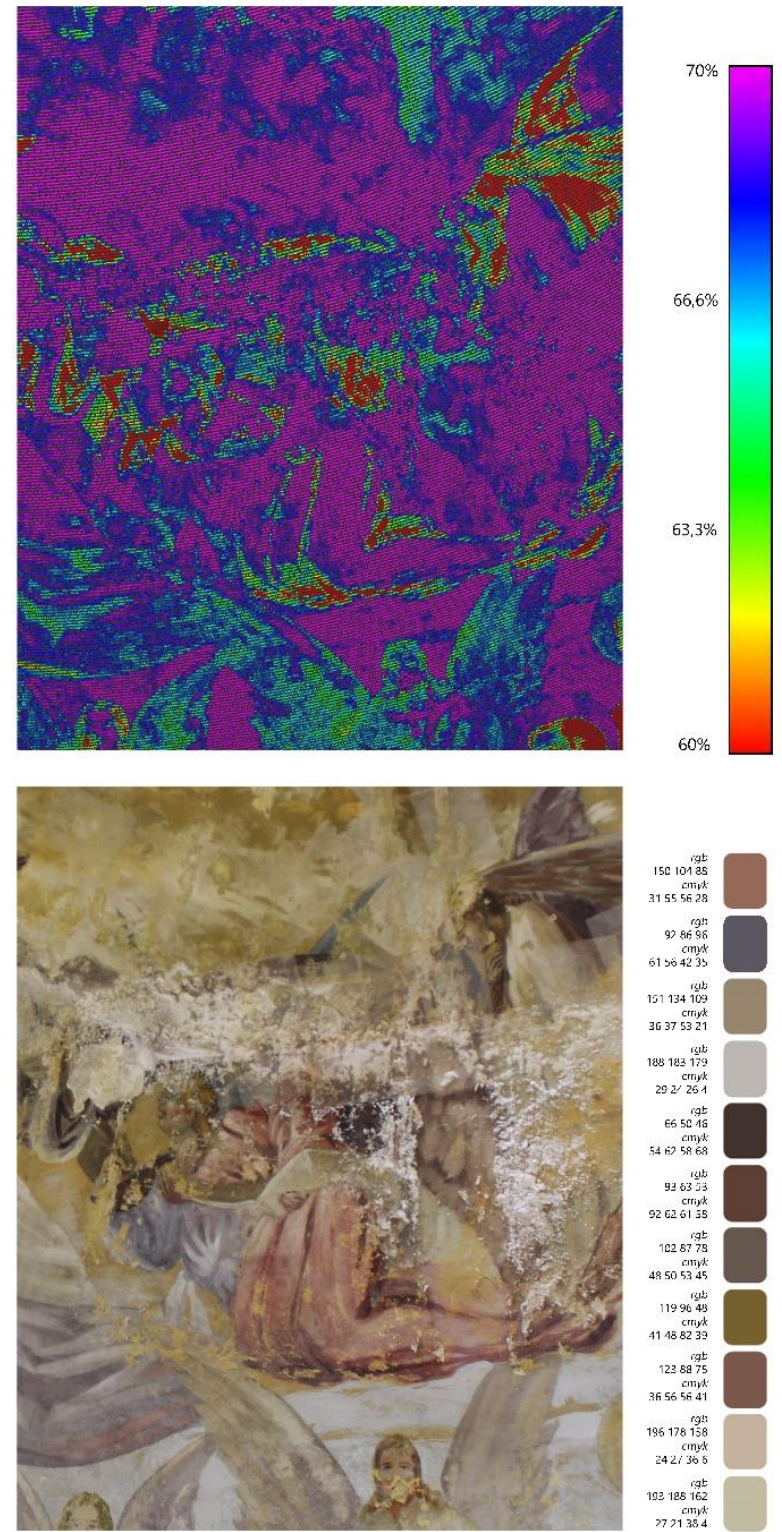

Figure 6. Reflectance map and colour classification for a detailed portion of the damaged fresco. The variations highlight portions with inhomogeneous and inconsistent behaviour. 
A previous visual inspection carried out on the extrados has already made it possible to trace these portions back to areas of the dome surface where adequate insulation, now installed, was not present (Fig. 8).
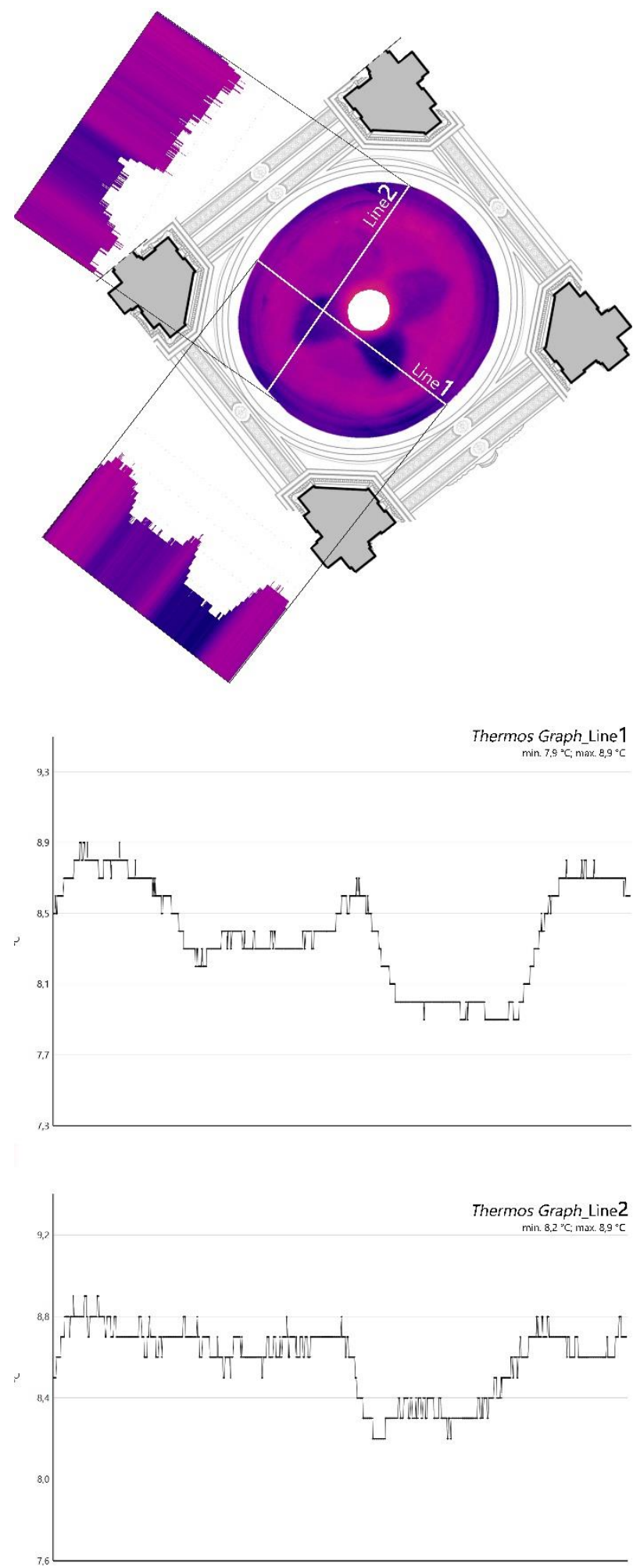

Figure 7. Model of the thermal behaviour of the dome. The extracted graphs show the 4 coldest areas and their temperature variations.
Finally, in order to correlate and quantify the maximum displacement values, both positive and negative, with actions of material loss or patina superposition, the deviation of the dome with respect to a primitive reference geometry was evaluated. Using some mathematical algorithms, such as the RANSAC implemented in the Cloud Compare software, the primitive geometry - a sphere - tangent to the inspected surface was computed, varying the computation parameters in order to obtain the best fitting. However, since the basic geometry of the dome is an ellipse and not a circle, the precise geometric model of revolution was also generated according to the values of the horizontal radius of curvature and the vertical plane. The deviation maps returned an almost total adherence between the elements considered, since, in this specific case, these were portions with millesimal thickness variations. However, once again, the detailed visual and photographic investigation that was carried out proved to be fundamental as it highlighted the dual nature of the affected parts. In particular, the dome is affected, in certain areas, only by a loss of surface colour and therefore by phenomena of "subtractive" degradation; in others, the nature of the degradation seems to be of an "additive" type, with the manifestation of superimposed patinas. By cross reading the material classification tables, the results of the reflectance mapping and the study of the thermal states, it was possible to begin an initial mapping of the alteration and degradation phenomena that affect the pictorial layers under investigation. Applying the indications of UNI11182:2006 standard for the cataloguing, the two phenomena highlighted above were respectively traced back to the lacuna (subtractive phenomenon) and to efflorescence (additive phenomenon). For each of these, thanks to the materials collected during the architectural survey campaign and produced in the research - the integrated point cloud - it was possible to begin to provide an initial quantitative estimation of the surface extension of the affected areas, to make an idea of the relevance of the phenomena in progress.

Clearly, further in-depth studies with detailed surveys and continuous monitoring are necessary as a continuation of the work.

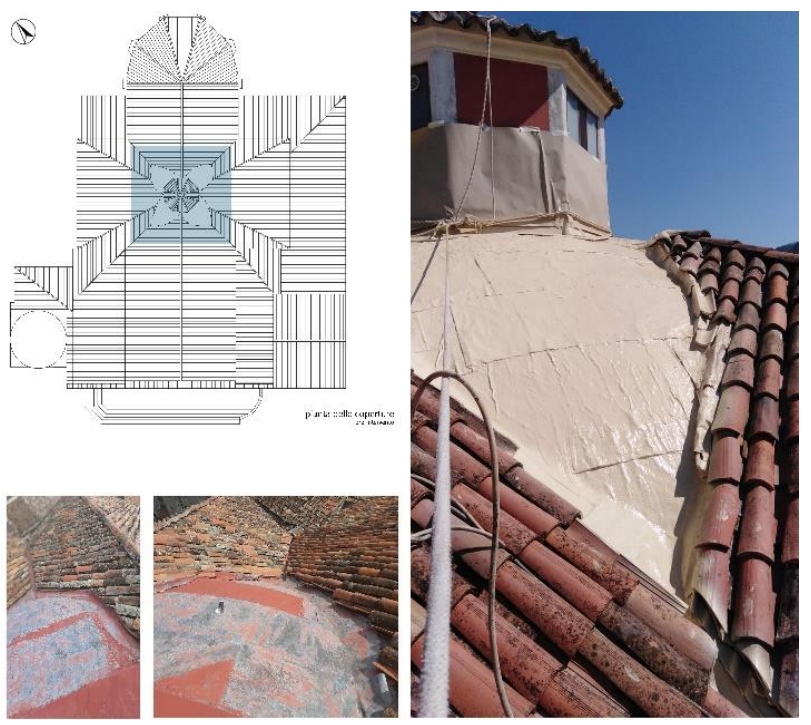

Figure 8. Situation at the extrados of the dome. It is possible to clearly see the 4 areas without waterproofing. 


\section{CONCLUSIONS}

The study applied to an asset of the $\mathrm{CH}$, an analysis methodology based on the possibility of integrating and extracting essential information for preventive conservation actions, simply by elaboration of the geometric model derived from the architectural survey.

The work was conceived to support a mainly qualitative assessment regarding a possible relationship between microenvironmental variations and visually perceived degradation phenomena in order to provide a first indication and evaluation of the conservation status of the investigated surfaces.

The interesting aspect lies in the possibility of conducting the analyses and relative evaluations through mathematical elaborations which are reiterable and objective. In addition, as these elaborations are executed on the models derived from the architectural survey, they allow maximum exploitation of these outputs. Combining, therefore, the mathematical elaborations of digital representations with the necessary critical interpretation of the data by the human being - the specialist - (an aspect that the research clearly shows), it is possible to direct the most appropriate choices for in-depth diagnostics - even with destructive tests - which are, however, carried out on more restricted and targeted areas, circumscribing the field of action and reducing waste and damage to the historical heritage.

In the specific case study, thanks to the data coming from the thermal imaging camera, interrelated to the critical study of the geometric, colour and reflectance data, the presence of humidity was detected in regions that are not visible on the surface and, for this reason, must be monitored in order to avoid the manifestation of further degradation phenomena, involving plaster detachment in larger areas and the addition of inconsistent patinas.

The analyses produced so far define the input for the planning of subsequent actions.

\section{ACKNOWLEDGEMENTS}

The research was coordinated by Prof. Massimiliano Campi and Prof. Antonella di Luggo. The study is part of the scientific cooperation agreement signed between the Interdepartmental Research Centre Urban|Eco of the University of Naples Federico II (Scientific Directors prof. Massimiliano and arch. Valeria Cera) and the Diocese of Teggiano-Policastro, in the person of the Vicar General, don Giuseppe Radesca.

The author wishes to thank all the architects and researchers who contributed to the logistical and data collection phases.

A special thanks goes to MicroGeo and Michele Cirignano for providing the TESTO890 thermal imaging camera and the 3DF Zephyr software for data processing.

\section{REFERENCES}

Adamopoulos, E., Rinaudo, F., 2021. Close-Range Sensing and Data Fusion for Built Heritage Inspection and Monitoring - A Review. Remote Sensing, 13(19), 3936.

Bakalos, N., Doulamis, N., Doulamis, A., 2020. Multispectral Monitoring of Microclimate Conditions for Non-destructive Preservation of Cultural Heritage Assets. In A. Kavoura et al. (eds.), Strategic Innovative Marketing and Tourism, 641-646. Springer, Cham.

Brumana, R., Ioannides, M., Previtali, M. 2019. Holistic Heritage Building Information Modelling (HHBIM): from nodes to hub networking, vocabularies and repositories. International
Archives of the Photogrammetry, Remote Sensing and Spatial Information Sciences, XLII-2/W11, 309-316.

Capone, M., Lanzara, E., Cera, V., 2019. Modelli parametrici per l'interpretazione dei Big Data: la cappella Caracciolo di Vico nella Chiesa di S. Giovanni a Carbonara a Napoli. In P. Belardi (Ed.), Riflessioni: l'arte del disegno/Il disegno dell'arte, 489-500. Roma: Gangemi.

Cera, V., 2021. La manipolazione di modelli discreti per orientare l'indagine diagnostica per il restauro. In R. A. Genovese (Ed.), Il patrimonio culturale tra la transizione digitale, la sostenibilità ambientale e lo sviluppo umano. Cultural Heritage in digital transition, environmental sustainability and human development, 167-190. Napoli: Giannini Editore.

Cera, V., Campi, M., 2021. Segmentation protocols in the digital twins of monumental heritage: a methodological development. DisegnareCon, 14(26), 14.1-14.10.

Cera, V., 2020. Semantics and Architecture: Reflections and Method Proposal for the Recognition of Semantically Defined Architectural Forms. In C.M. Bolognesi, C. Santagati (Eds), Impact of Industry 4.0 on Architecture and Cultural Heritage, 330-356. IGI Global.

Cera, V., Garcia, L. A., 2018. Dalla nuvola di punti al progetto di restauro. L'estrazione di dati per la valorizzazione dell'antica fortificazione di Casertavecchia. In A. Marotta, R. Spallone (Eds.), Defensive Architeture of the Mediterranean, 981-988. Politecnico di Torino.

Colucci, E., Xing, X., Kokla, M., Mostafavi, M.A., Noardo, F., Spanò, A. 2021. Ontology-Based Semantic Conceptualisation of Historical Built Heritage to Generate Parametric Structured Models from Point Clouds. Applied Sciences, 11, 2813.

Croce, V., Caroti, G., De Luca, L., Jacquot, K., Piemonte, A., Veron, P., 2021. From the Semantic Point Cloud to HeritageBuilding Information Modeling: A Semiautomatic Approach Exploiting Machine Learning. Remote Sensing, 13(3), 461.

Dahaghin, M., Samadzadegan, F., Javan, F. D., 2021. Precise 3D extraction of building roofs by fusion of UAV-based thermal and visible images. International Journal of Remote Sensing, 42(18), 7002-7030.

Lee, S., Lee, S., 2020. Surface IR Reflectance Estimation and Material Recognition using ToF Camera. 25th International Conference on Pattern Recognition (ICPR), 6463-6470.

Lin, D., Jarzabek-Rychard, M., Tong, X., Maas, H. G., 2019. Fusion of thermal imagery with point clouds for building façade thermal attribute mapping. ISPRS Journal of Photogrammetry and Remote Sensing, 151, 162-175.

Matrone, F., Grilli, E., Martini, M., Paolanti, M., Pierdicca, R., Remondino, F., 2020. Comparing Machine and Deep Learning Methods for Large 3D Heritage Semantic Segmentation. International Journal of Geo-Information, 9(9), 535. 